\title{
Depression and its associated factors among the older adults in rural, Tamilnadu, India
}

\author{
K. Bincy *, M. Logaraj, Balaji Ramraj \\ Department of Community Medicine, SRM Medical College Hospital and Research center, SRM Institute of Science \& Technology, Kattankulatur, Tamilnadu, India
}

\section{A R T I C L E I N F O}

\section{Keywords:}

Depression

Elderly

Illiteracy

Dependency

Risk factors

\begin{abstract}
A B S T R A C T
Background: Depression is a significant public health concern, especially among older adults due to its distressing morbidity and mortality rate. This study aimed to assess the prevalence of depression and the associated risk factors among older adults (age $\geq 60$ years) in Tamilnadu, India.

Materials and methods: A community-based cross-sectional study was carried out from July 2016 to May 2018 among the older adults in the rural area of three districts of Tamil Nadu, India. Geriatric Depression Scale item 15 (GDS-15) was used to assess depression with face to face interviews from 7200 participants. Descriptive statistics and multivariable logistic regression analysis were employed. Adjusted odds ratio (OR) with a 95\% confidence interval was used to calculate the significance.

Results: Prevalence of depression among older adults were found to be $67.5 \%$ (95\% CI-0.66-0.68). The multivariable logistic regression model revealed that older adults above 80 years (OR $=1.91$; CI $=0.885-1.344$ ), female sex ( $\mathrm{OR}=0.88 ; 95 \% \mathrm{CI}=0.803-0.982$ ), widow ( $\mathrm{OR}=0.88 ; 95 \% \mathrm{CI}=0.77-1.00)$, living with children $(\mathrm{OR}=0.86,95 \% \mathrm{CI}=0.77-0.97)$, lack of family support $(\mathrm{OR}=1.48 ; \mathrm{CI}=1.321-1.638)$, and physically dependent $(\mathrm{OR}=1.01 ; \mathrm{CI}=0.88-1.15$ ) were associated with depression among older adults. Additional to this, people with diabetes $(\mathrm{OR}=1.15 ; \mathrm{CI}=1.007-1.33)$, and with the history of fall $(\mathrm{OR}=1.28 ; \mathrm{CI}=1.017-1.620$ ) also associated with the depression.

Conclusion: Prevalence of depression among the elderly population is reported to be high in this study. Screening the elderly for depression at the primary care level helps in early detection of depression. This suggests the need for community-based interventions for effective management of older adults with chronic diseases.
\end{abstract}

\section{Background}

Depression is an essential mental health challenge because of its devastating nature, which is the second global burden of the disease that might emerge as a disorder of life with disability. ${ }^{1}$ In 2015 , it was estimated that 800,000 older adults committed suicide annually, and depression is the single most significant contributor to global disability $97.5 \%{ }^{2}$ Around the world, approximately 322 million people get affected with depression with the worldwide prevalence of the range $10-20 \%$ depending on cultural situations. ${ }^{3,4}$ A developing country like India comprises of $8.6 \%$ of elderly persons (60 years and above) of the total population (India Census 2011), which is proposed to reach $19 \%$ by $2050 .{ }^{5}$ Thus, depression among the elderly population is likely to be a significant cause of disease burden in the future. Chronic diseases, loss of income, elderly disrespect, limited mobility, bereavement, and isolation are leading risk factors for depression among the elderly population, in addition to common risk factors in all age groups. ${ }^{6}$ Most of the time, the presentation of the depression in old age is masked by memory status with psychological symptoms; still, these problems are secondary to depression concern. It has destructive consequences and contributes significantly to negative thoughts in this period of life. ${ }^{7}$ It also decreases the quality of life and limits the prognosis of the chronic diseases that further worsen the disability. Therefore, elderly persons with depression have significantly higher mortality of suicidal and non-suicidal incidence. ${ }^{8}$ So it is a need for early recognition, and social control of depression among these risk groups would be of great benefit for them to have a better quality of life. However, low and middle-income countries' health care systems like India are not resilient adequate to deal with mental health problems, including depressive disorders. Previous epidemiological studies also provide the list of various contributing risk factors for the depression, with the prevalence ranging from 6 to $80 \%$ among the elderly populations. ${ }^{9,10}$ Besides, compared with other

\footnotetext{
* Corresponding author.

E-mail address: bincylilly@gmail.com (K. Bincy).
} 
findings, evidence of depressive disorders tends to be relatively weak and the level of its burden among older adults is not well addressed in the state of Tamilnadu. ${ }^{11}$ Lack of adequate evidence about depression in older adults may be a factor that contributes to weak or inconsistent mental health care at the community level. ${ }^{12,13}$ Therefore, this study aimed to investigate the prevalence of depression and its associated factors among older adults in the rural area of three districts, Tamilnadu.

\section{Materials and Methods}

This community-based cross-sectional study was carried out from July 2016 to May 2018 in the rural area of three districts of Tamil Nadu, India. Study protocols were reviewed and approved by the ethical review board of the host institution. All the participants were provided the informed consent in written, and explained to them in their local language with the explicit assurance that the data provided by them would remain confidential and will not be affected by study participation or protocols. The study population were residents of three district, older adults of 60 years and above residing in that area for more than one year. The inclusion criteria were kept broad to optimize generalizability to community health settings. Persons not consenting were excluded, and with whom communication was difficult due to any reason (hearing loss and language problems) and subjected those who were terminally ill, with any prior psychiatric illness also were excluded from the study.

\subsection{Sampling technique}

Multistage stratified Random sampling method was used,.Three district Chengalpattu, Kancheepuram, Thiruvannamalai of Tamil Nadu were selected for the study, and one rural primary health center (PHC) from each district was chosen randomly covering a total of 90,000-100000 population. Based on the literature review, the estimated prevalence rate for older adults is taken as $8 \%$, with a $5 \%$ marginal error. ${ }^{14}$ The sample size was calculated as 7200 . The number of villages in each selected PHC was enlisted, and towns were selected by lottery method. Total of 2400 elderly participants were interviewed randomly from each selected PHC village until the estimated sample size achieved.

\subsection{Study tool}

Interview schedule containing face to face interviews with semistructured questions of both closed and open-endedafter being tested in a small pilot study of 30 participants to validate its efficacy was used. Socio-demographic profile assessment included questions on age, gender, socioeconomic status (SES), occupation, type of house, years of study, financial dependency. Assessment of functional ability was assessed using the Katz Index of independence in activities of daily living which has six functions; bathing, dressing, toileting, transferring, continence and feeding. A score of 6 indicates the full service, 4 indicates moderate impairment and two or less indicates severe functional impairment. ${ }^{15}$ Health Behavioral assessment was done with the particulars of Smoking, Alcohol Consumption, Tobacco usage and sleep pattern. Evaluation of physical health was done by general examination followed by screening for chronic disease and morbidities through previous available medical records. Visual impairment (Snellen's chart), Hearing impairment (whispering test), Gait disturbances (Time Up and Go [TUG Test]) were assessed for all the participants. Cognitive impairment was evaluated using Mini-Mental Scale Examination (MMSE). Scoring 24 and above indicates normal cognitionwhile scoring below that indicates cognitive impairment. ${ }^{16}$ Geriatric depression scale 15 (GDS short version) was used to assess the depression. ${ }^{17}$ A score of $0-5$ is standard. A score $>5$ suggests mild, and $\geq 10$ is severe depression.

\subsection{Statistical analysis}

Data were entered using Microsoft Excel 2010 and analyzed using Statistical Package for Social Sciences version 18 (PASW Statistics for Windows, Chicago: SPSS Inc.). Descriptive statistics were used, and results were expressed in frequencies and percentages. Categorical variables were compared using the Pearson Chi-Square test. Odds ratio (OR) and $95 \%$ confidence interval $(\mathrm{CI})$ were calculated for all risk factors. Multiple logistic regression was done to identify significant independent risk factors for people with depression.

\section{Results}

\subsection{Socio-demographic characteristics of participants}

A total of 7200 older adults participated, and more than half, 4377 $(60.8 \%)$ were females. Most of them belonged to the age group of 60-69 years $(71.8 \%)$. The majority of them $(78.7 \%)$ were married and living with their children $(58.5 \%)$, while $25.1 \%$ were living only with their spouse. Nearly $74.4 \%$ of the participants were illiterate, primary, middle, and secondary schooling were $16.6 \%, 5.4 \%$,and $3 \%$ respectively. Among the respondents, $96 \%$ were Hindu, and most of them staying in semi pukka houses $(46.2 \%)$ followed by the pucca house $(39.9 \%)$, respectively (Table: 1 ). The prevalence of the depression among the older adults was found to be $67.5 \%(95 \% \mathrm{CI}=0.66-0.68)$.

\subsection{Factors associated with depression}

Our study showed that older adults with the age of above 80 years, lack of family support, retirement, with dementia, diabetes, and history of fall were significantly and independently associated with depression (see Table 1). However, depression had no significant association with sex, marital status, social supports, substance use, and other clinical conditions. Older adults above 80 years of age were 1.9 times more likely to have depression compared to their counterparts [OR $=1.91$, 95\% CI (0.88-1.33)]. Older individuals with a lack of family supports were 1.4 times more likely to have depression than the individuals with support $[\mathrm{OR}=1.48,95 \%$ CI $(1.32-1.638)]$. Older diabetics were 1.1 times more likely to be depressed than non-diabetics $[\mathrm{OR}=1.14,95 \% \mathrm{CI}$ (1.00-1.33)]. Older individuals with dementia problem were 3.3 times more likely to have depression than their counterparts [OR $=3.3,95 \%$ CI (2.24-5.14)]. Individuals with a history of falls were 1.2 times more likely to have depression than the healthy older adults [OR $=1.28,95 \%$ CI 91.01-1.62)] (Table 2).

\section{Discussion}

The present study was an attempt to assess the prevalence of depression and its associated factors among the elderly population. In this study, the prevalence of depression among the older adult population was found to be $67.5 \%$, which is slightly higher (35.5\%) than the previous studies conducted in Tamil Nadu. ${ }^{18}$ The finding also in line with that of other community based cross-sectional studies done in Brasil (37.2\%), ${ }^{19}$ Sudan (37.5\%), Vietnam $(26.2 \%),{ }^{20}$ and Pakistan (27.4\%). ${ }^{21}$ Still, our finding was comparatively higher than the outcome of a meta-analysis from the 56 community-based studies in South, North and Western region of the Indian population, where the pooled prevalence of depression was $34.4 \%$ in older adults, ${ }^{9}$ however these findings in line with pooled prevalence (57\%) of Tamilnadu state a part of south Indian population alone. Another systematic review of 26 studies among elderly Iranian people estimated the prevalence of depression (43\%) to be lesser than the current findings. ${ }^{22}$ This disparity might be due to the difference in the cultural background, genetics, and environmental factors or methodological/sampling methods or screening tools. Most of them have used Geriatric Depression Scale (GDS), whereas others also used Public Health Questionnaire (PHQ), Center for Epidemiologic 
Table 1

Frequency distribution of Socio-Demographic Profile.

\begin{tabular}{lll}
\hline Variable & Frequency $(\mathrm{n}=7200)$ & Percentage (\%) \\
\hline Age & & 71.8 \\
60-69 years & 5175 & 22.3 \\
70-79 years & 1606 & 5.8 \\
Above 80 & 419 & \\
Sex & & 39.2 \\
Male & 2823 & 60.8 \\
Female & 4377 & \\
Marital status & & 78.7 \\
Married & 5671 & 1 \\
Unmarried & 79 & 17.7 \\
Widow & 1275 & 2.3 \\
Widower & 171 & 74.4 \\
Education & & 16.6 \\
Illiterate & 5358 & 5.4 \\
Primary & 1200 & 3 \\
Middle & 394 & 0.38 \\
Secondary & 216 & 0.05 \\
Undergraduate & 28 & \\
Postgraduate & 4 & 96 \\
Religion & & 1 \\
Hindu & 6915 & 2.8 \\
Muslim & 79 & 39.9 \\
Christian & 206 & 46.2 \\
House type & & 13.8 \\
Pucca & 3330 & \\
Semi pucca & 996 & \\
Katcha & & \\
\hline
\end{tabular}

Studies Depression Scale (CES-D), Hamilton Depression Rating Scale (HDRS), and Beck Depression Inventory (BDI) for assessing the depression. Standardization of the methods and screening scale is essential for the assessment of the depression among elderly persons. Since most of the studies had used the GDS and CES-D as a screening instrument, it is likely to bemore sensitive than others. ${ }^{23}$ Findings from other low and middle-income countries also registered a higher $(>35 \%)$ rate of depression in the elderly population. Word Health Organization report from the Global Ageing and Adult Health (2007-10) also revealed that older adults in India have a high prevalence of depression than the other low and middle-income countries (China, Ghana, Mexico, Russia, and South Africa). ${ }^{24,25}$ In our study, older adults with above 80 yrs had a higher prevalence of depression, which may be due to a lack of opportunity to interact with others to share their feelings and thoughts and have no support. Older adults with a lack of family support have 1.48 times more likely to develop depression than others.

It may be due to the economic burden, which is essential to manage the daily routine living expenses. This study also found that older adults who had diabetes were 1.15 times more likely to develop depression compared to non-diabetics. This may be due to the nature of the condition, along with medical expenses and fear of control of blood sugar level. Older adults with dementia were 3.3 times more likely to develop depression than others. This is quite a common condition for everyone over 60 yrs, but most of the previous studies excluded the elders with dementia to limit the false positive cases of depression. Other studies also showed that females, with children's separation and divorce, were significantly associated with older adult depression, ${ }^{26-28}$ but in our study, these variables had no significant association. The disparity could be due to variation in the sampling of the population, sample size, measurement tools, and other social-cultural backgrounds among participants.

Major strengths of this study include larger sample size and the use of a reliable, standardized instrument that was validated for elderly population. This study contained some limitations as well. Since GDS-15 is a tool for screening, generalizability of depression prevalence has its limitations with respect to diagnostic criteria. The assessment of

Table 2

Multiple Logistic regression analysis of depressive disorder among older adults.

\begin{tabular}{|c|c|c|c|c|c|c|}
\hline Risk Factors & Depression Present n(\%) & Depression Absent n(\%) & Total n(\%) & OR & 95\% C.I & P-Value \\
\hline \multicolumn{7}{|l|}{ Age } \\
\hline 60-69 Years & $1726(33.4 \%)$ & $3449(66.6 \%)$ & $5175(71.8 \%)$ & 1 & & \\
\hline 70-79 Years & $468(29.2 \%)$ & $1138(70.8 \%)$ & $1606(22.3 \%)$ & 0.82 & $0.727-0.928$ & 0.001 \\
\hline 80 Above & $148(35.4 \%)$ & $271(64.6 \%)$ & $419(5.8 \%)$ & 1.91 & $0.885-1.344$ & 0.413 \\
\hline \multicolumn{7}{|l|}{ Sex } \\
\hline Male & $963(34.1 \%)$ & $1860(65.9 \%)$ & $2823(39.2 \%)$ & 0.88 & $0.803-0.982$ & 0.02 \\
\hline Female & $1379(31.6 \%)$ & $2998(68.4 \%)$ & $4377(60.7 \%)$ & & & \\
\hline \multicolumn{7}{|l|}{ Marital Status } \\
\hline Married & $1885(33.2 \%)$ & $3789(66.7 \%)$ & $5674(78.7 \%)$ & 1 & & \\
\hline Unmarried & $16(20.3 \%)$ & $63(79.7 \%)$ & $79(1 \%)$ & 0.51 & $0.29-0.88$ & 0.01 \\
\hline Widow & $390(30.5 \%)$ & $885(69.5 \%)$ & $1275(17.7 \%)$ & 0.88 & $0.77-1.00$ & 0.06 \\
\hline Widower & $51(29.8 \%)$ & $120(70.1 \%)$ & $171(2.3 \%)$ & 0.85 & $0.61-1.1$ & 0.35 \\
\hline \multicolumn{7}{|l|}{ Social Support } \\
\hline Family & $2080(33.3 \%)$ & $4154(66.5 \%)$ & $6234(86.5 \%)$ & 1 & & \\
\hline Friends & $86(28.9 \%)$ & $211(71 \%)$ & $297(4.15 \%)$ & 0.81 & $0.63-1.05$ & 0.11 \\
\hline Community & $37(29.3 \%)$ & $89(70.6 \%)$ & $126(1.75 \%)$ & 0.83 & $0.56-1.22$ & 0.34 \\
\hline None & $138(25.4 \%)$ & $404(74.5 \%)$ & $542(7.5 \%)$ & 0.68 & $0.55-0.83$ & 0.0001 \\
\hline \multicolumn{7}{|c|}{ Take Care Of Elderly } \\
\hline Spouse & $661(36.5 \%)$ & $1153(63.5 \%)$ & $1814(25.1 \%)$ & 1 & & \\
\hline Children & $1397(33.1 \%)$ & $2816(66.8 \%)$ & $4213(58.5 \%)$ & 0.86 & $0.77-0.97$ & 0.01 \\
\hline In-Laws & $49(17.6 \%)$ & $228(82 \%)$ & $277(3.8 \%)$ & 0.37 & $0.27-0.51$ & 0.0001 \\
\hline Grand Children & $31(22.6 \%)$ & $106(77.3 \%)$ & $137(1.9 \%)$ & 0.51 & $0.33-0.76$ & 0.0001 \\
\hline None & $204(26.8 \%)$ & $555(73.1 \%) 759(10.5 \%)$ & & 0.64 & $0.53-0.77$ & 0.0001 \\
\hline \multicolumn{7}{|c|}{ Lack Of Family Support } \\
\hline Yes & $417(26 \%)$ & $1183(74 \%)$ & $1600(22.2 \%)$ & 1.48 & $1.321-1.638$ & 0.0001 \\
\hline No & $1925(29 \%)$ & $3675(55.6 \%)$ & $6600(91.6 \%)$ & & & \\
\hline \multicolumn{7}{|l|}{ Diabetes } \\
\hline Yes & $333(29.9 \%)$ & $782(70.1 \%)$ & $1115(15.5 \%)$ & 1.15 & $1.007-1.33$ & 0.03 \\
\hline No & $2009(43.1 \%)$ & $4076(66.9 \%)$ & $6085(84.5 \%)$ & & & \\
\hline \multicolumn{7}{|l|}{ Dementia } \\
\hline Yes & $26(13 \%)$ & $174(87 \%)$ & $200(2.7 \%)$ & 3.3 & $2.2404-5.1479$ & 0.08 \\
\hline No & $2316(32 \%)$ & $4683(66.9 \%)$ & $6999(97.2 \%)$ & & & \\
\hline \multicolumn{7}{|l|}{ History Of Fall } \\
\hline Yes & $103(27.5 \%)$ & $271(72.4 \%)$ & $374(5 \%)$ & 1.28 & $1.017-1.620$ & 0.034 \\
\hline No & $2239(33 \%)$ & $4587(67 \%)$ & $6826(95 \%)$ & & & \\
\hline
\end{tabular}


comorbidities was based on history and medical records alone.

\section{Conclusion}

This study showed that the prevalence of depression among older adults was high. Above 80 years of age, lack of family support, diabetes, and falling history were significantly associated with depression. Need to provide further emphasis in identifying and treating depression, especially the older adults above 80 years of age, lack of family support, diabetes, lack of family support, and falling history.

\section{Ethics statement}

Intuitional Ethics Committee (IEC) for human has approved the project titled as "Prevalence and various contributing factors for depression among the older adults at Chennai, Tamilnadu, India" as per the Indian Council of Medical Research (ICMR) guideline with the reference no: SRM/PG/2017-08.

\section{References}

1 Patterson AS, et al. Investigating global mental health: contributions from political science. Global public health; 2020:1-13.

2 Ge D, et al. Exploring the risk factors of suicidal ideation among the seniors in Shandong, China: a path analysis. J Affect Disord. 2017;207:393-397.

3 Friedrich M. Depression is the leading cause of disability around the world. Jama. 2017;317(15), 1517-1517.

4 Harerimana B, Forchuk C, O'Regan T. The use of technology for mental healthcare delivery among older adults with depressive symptoms: a systematic literature review. Int J Ment Health Nurs. 2019;28(3):657-670.

5 Agarwal A, et al. Population aging in India: facts, issues, and options. In: Population Change and Impacts in Asia and the Pacific. Springer; 2020:289-311.

6 Lengenfelder J, et al. Psychological assessment of the elderly. In: Handbook of Psychological Assessment. Elsevier; 2019:505-532.

$7 \mathrm{Kim} \mathrm{H}$, et al. Depression prediction by using ecological momentary assessment, actiwatch data, and machine learning: observational study on older adults living alone. JMIR mHealth and uHealth. 2019;7(10):e14149.

8 Wei J, et al. The association of late-life depression with all-cause and cardiovascular mortality among community-dwelling older adults: systematic review and metaanalysis. Br J Psychiatr. 2019;215(2):449-455.
9 Pilania M, et al. Prevalence of depression among the elderly (60 years and above) population in India, 1997-2016: a systematic review and meta-analysis. BMC Publ Health. 2019;19(1):832.

10 Barua A, Kar N. Screening for depression in elderly Indian population. Indian J Psychiatr. 2010;52(2):150.

11 Chauhan P, et al. A study on prevalence and correlates of depression among elderly population of rural South India. Int. J. Community Med. Public Health. 2016;3: 236-239.

12 Patel V, et al. The magnitude of and health system responses to the mental health treatment gap in adults in India and China. Lancet. 2016;388(10063):3074-3084.

13 De Costa A, Diwan V. 'Where is the public health sector?': public and private sector healthcare provision in Madhya Pradesh, India. Health Pol. 2007;84(2-3):269-276.

14 Kumar V. Ageing in India-an overview. Indian J Med Res. 1997;106:257.

15 Shelkey M, Wallace M. Katz index of independence in activities of daily living (ADL). Int J Older People Nurs. 2012;2(3):204-212.

16 Creavin ST, et al. Mini-Mental State Examination (MMSE) for the detection of dementia in clinically unevaluated people aged 65 and over in community and primary care populations. Cochrane Database Syst Rev. 2016;(1).

17 Sheikh JI, Yesavage JA. Geriatric Depression Scale (GDS): recent evidence and development of a shorter version. Clin Gerontol: The Journal of Aging and Mental Health. 1986;5(1-2):165-173.

18 Buvneshkumar M, John K, Logaraj M. A study on prevalence of depression and associated risk factors among elderly in a rural block of Tamil Nadu. Indian J Publ Health. 2018;62(2):89.

19 Silva PO, et al. Prevalência de sintomas depressivos e seus fatores associados em idosos atendidos por um centro de referência. Revista Brasileira de Geriatria e Gerontologia. 2019;22(5).

20 Dao A, et al. Factors associated with depression among the elderly living in urban Vietnam. BioMed Res Int. 2018;2018, 2370284. https://doi.org/10.1155/2018/ 2370284.

21 Farooq S, et al. Prevalence of anxiety and depressive symptoms and their association with multimorbidity and demographic factors: a community-based, cross-sectional survey in Karachi, Pakistan. BMJ open. 2019;9(11).

22 Sarokhani D, et al. Prevalence of depression among iranian elderly: systematic review and meta-analysis. Iran J Psychiatry. 2018;13(1):55.

23 Behera P, et al. Screening instruments for assessment of depression. Indian J Med Specialities. 2017;8(1):31-37.

24 Organization WH, World Health Day. Ageing and Health: Toolkit for Event Organizers. World Health Organization; 2012, 2012.

25 Williams JS, et al. Risk factors and disability associated with low back pain in older adults in low-and middle-income countries. Results from the WHO study on global AGEing and adult health (SAGE). PloS One. 2015;10(6).

26 Zhang L, et al. The prevalence of depressive symptoms among the older in China: a meta-analysis. Int J Geriatr Psychiatr. 2012;27(9):900-906.

27 Girgus JS, Yang K, Ferri CV. The gender difference in depression: are elderly women at greater risk for depression than elderly men? Geriatrics. 2017;2(4):35.

28 Chatterji S, et al. The health of aging populations in China and India. Health Aff. 2008;27(4):1052-1063. 